\section{p-Toluenesulfonate in Landfill Leachates: Leachability from Foundry Sands and Aerobic Biodegradation}

SONJA RIEDIKER, †,

SABINE RUCKSTUHL, $\S$

MARC J.-F. SUTER, *,

ALASDAIR M. COOK, $\neq A N D$

WALTER GIGER $\S$

Swiss Federal Institute for Environmental Science and

Technology (EAWAG), CH-8600 Dübendorf, Switzerland, and

Faculty of Biology, University of Konstanz,

D-78457 Konstanz, Germany

p-Toluenesulfonate (pTS) was found at concentrations between 9.6 and $48.8 \mathrm{mg} / \mathrm{L}$ in leachates from two Swiss landfill sections where foundry wastes are stored. pTS represented $\leq 33 \%$ of the nonpurgable organic carbon (NPOC) in the leachates. A standard test showed that pTS is easily leached from foundry sands that contained $1 \%(w / w)$ of a technical hardener consisting of toluenesulfonates. Hence, the hardener is a likely source of pTS in the landfill leachates. Furthermore, analyses using liquid chromatography coupled to mass spectrometry and UV absorption detection indicated that the hardener also was the source for toluene-2,4-disulfonate, benzenesulfonate and 0 - and $m$-toluenesulfonate, all of which were detected in the landfill leachates. Modified OECD screening tests with pure pTS or hardener as carbon source and landfill leachate as inoculum indicated that aerobic bacteria using pTS for growth are present in the landfill leachates. The intermediates $p$-sulfobenzyl alcohol and $p$-sulfobenzoate gives strong evidence for a degradation pathway common to Comamonas testosteroni.

\section{Introduction}

Benzene- and naphthalenesulfonates are high production volume, xenobiotic chemicals, which are readily soluble in water, contained in many commercial products. Correspondingly, they are found in surface waters (1-3) because of their incomplete degradation in sewage treatment plants $(4,5)$ and in pollution plumes from waste dumps and superfund sites $(6,7)$. The investigations of leachates from four landfills with varying waste composition showed several of these compounds at various concentration levels $(\mu \mathrm{g} /$ L-mg/L) (8). Besides other sulfonated aromatics such as benzenesulfonate (BeS) and toluene-2,4-disulfonate (T-2,4dS), p-toluenesulfonate (pTS) was found at unusually high concentrations $(9.6-48.8 \mathrm{mg} / \mathrm{L})$ in leachates from two recent

\footnotetext{
* Corresponding author phone: +41-1-823 5479; fax: +41-1-823 5028; e-mail: suter@eawag.ch.

† Present address: Nestlé Research Center, Vers-chez-les-Blanc, 1000 Lausanne 26, Switzerland.

¥ University of Konstanz.

$\S$ Swiss Federal Institute for Environmental Science and Technology (EAWAG).
}

sections of a landfill site, where it contributed up to $33 \%$ to the leachate NPOC (8), and was thus the most relevant pollutant.

pTS $\left(\mathrm{pK}_{\mathrm{a}} 0.7, \mathrm{~K}_{\text {ow }} 0.78\right)$ is used both as an intermediate in the production of many chemical products (e.g. phenolic antioxidants, tanning agents) and as an additive to lubricants, washing powders, and cleaning agents ( $250 \mathrm{t}$ of sodium pTS used in Germany in 1990) (9). The European consumption of pTS in 1983 was $27000 \mathrm{t}, 38 \%$ of which was used in foundries (9), where pTS serves as a hardener in one specific production procedure for foundry moulds and cores used for casting. The moulds and cores, both consisting of $98 \%$ quartz sand, $1 \%$ furanic resin, and $1 \%$ commercial hardener, are discarded after use.

Even though these foundry wastes are reported to beassociated with insignificant environmental problems (10-12), the analysis of a commercial hardener and leaching tests with foundry sands show that pTS, BeS, and T-2,4-dS in the leachates derives from the deposited foundry wastes. A corresponding 58t of pTS were introduced annually into the two sections of the landfill in question from 1983 to 1990.

The aerobic biodegradation of pTS and BeS has been known for over 30 years, and several degradative pathways have been elucidated (13). However, no data are available about the degradation of T-2,4-dS. Due to the elevated pTS concentration in the landfill leachatesmicroorganismsusing pTS for growth were expected to be absent in the anoxic landfill site. Under anaerobic conditions, only desulfonation of aromatic sulfonates in the absence of bioavailable sulfur has been observed (13). Degradation tests using anoxic landfill leachate as inoculum and done under conditions of nitrate or sulfate reduction confirmed the assumption that pTS, BeS, and T-2,4-dS are not degraded in an anoxic environment (14). However, the present study shows that the leachate collected from a landfill drain end whereatmospheric oxygen is present contains aerobic microorganisms that utilize pTS, BeS, but not T-2,4-dS.

\section{Experimental Section}

Chemicals and Materials. Benzenesulfonic acid, p-toluenesulfonic acid monohydrate, and diphenylamine-4-sulfonate are commercially available from Fluka AG (Buchs, Switzerland). p-Sulfobenzoic acid waskindly provided by Ciba-Geigy (Basel, Switzerland). The synthesis of toluene-2,4-disulfonate followed the procedure reported earlier (15). The hardener GRC (technical pTS solution, 65\% (w/w) including all positional isomers) and the binder Gremodur KN were obtained from Ashland-Südchemie Gremolith AG (Bazenheid, Switzerland). Thereferencecompounds were of varying qualities.

Tetrabutylammonium hydrogen sulfate (TBA) and formaldehyde (37\%) were purchased from Fluka AG (Buchs, Switzerland). Ammonium acetate $\left(\mathrm{NH}_{4} \mathrm{Ac}\right)$, potassium hydrogen phthalate, $\mathrm{D}(+)$ glucose monohydrate, potassium hydrogen carbonate, and all salts used for the mineral media of the biodegradation tests were purchased from Merck AG (Darmstadt, Germany), Aldrich (Buchs, Switzerland), or Fluka AG (Buchs, Switzerland). Cesium iodide was purchased from Aldrich (Buchs, Switzerland). The yeast extract was obtained from Biolife (Milano, Italy). All chemicals were of p.a.-grade. HPLC-grade methanol ( $\mathrm{MeOH})$ and water were bought from Scharlau (Barcelona, Spain).

Landfill Site. The landfill site consists of an old multicomponent section and five recent sections. Industrial and demolition wastes and road and shaft sludge have been deposited in two recent sections. Municipal solid waste 
incineration (MSWI) bottom ash and flue gas scrubber residues from a MSWI plant are landfilled in two further sections. The fifth section is used as composting site. The foundation of the recent sections is lined with a bituminous concrete layer. The leachates are collected by a drainage system that drains into the municipal sewerage without any pretreatment.

In March 1998, the leachate used for the biodegradation test was collected in a brown $1 \mathrm{~L}$ glass bottle in a drain downstream of a section were industrial, and demolition wastes are stored. The sample was transported in an icebox and immediately used to prepare the batch cultures.

Instruments. Measurements were conducted using a HPLC 1090L Series II coupled to a diode array detector from Hewlett-Packard Schweiz AG (Urdorf, Switzerland; LC/UVD) and a HP chromatograph Series 1100 with a variable wavelength UV detector from Hewlett-Packard Schweiz AG (Urdorf, Switzerland; LC/MS). The mass spectra were acquired on a Platform LC single quadrupolemass spectrometer equipped with an electrospray ionization interface from Micromass UK Ltd. (Manchester, United Kingdom). The measurements of NPOC and total organic carbon (TOC) were performed using a TOC-Analyzer TOC-5000 A with a SSM$5000 \mathrm{~A}$ module with a nondispersive infrared detector from Shimadzu Corporation (Kyoto, Japan).

Leaching Test According to DIN 38414 S4. Two Swiss foundries (Foundry I and II) kindly provided fragments of moulds and cores that were taken out of the production run before or after use. The fragments, originally consisting of $98 \%$ of quartz sand, $1 \%$ of the binder Gremodur KN, and $1 \%$ of the hardener GRC, were crushed and sieved to a particle size of maximum $0.5 \mathrm{~mm}$. This formulated sand ( $100 \pm 1 \mathrm{~g})$ was added to $1 \mathrm{~L}$ of doubly distilled water (leachant) in a 1 L laboratory bottle with screw-cap after both thesand sample and the bottled water had been autoclaved ( $121^{\circ} \mathrm{C}, 20 \mathrm{~min}$ ). The closed bottle was shaken $\left(130 \mathrm{~min}^{-1}\right)$ for $24 \mathrm{~h}$ at a constant temperature of $25^{\circ} \mathrm{C}$ in the dark. The test solution was filtered through $0.45 \mu \mathrm{m}$ cellulose nitrate filter (Sartorius $\mathrm{GmbH}$, Göttingen, Germany), which had been soaked in hot water (desalinated and low in total organic carbon). $\mathrm{pH}$ and conductivity were determined directly after filtration. For LC/UVD analysis, $20 \mathrm{~mL}$ of leachant was stabilized with 0.2 $\mathrm{mL}$ of formaldehyde. Prior to the analysis, every sample was diluted with doubly distilled water by a factor of 20 , and then $0.1 \mathrm{~mL}$ of the diluted sample and $15 \mu \mathrm{L}$ of diphenylamine4-sulfonate (internal standard: $44.25 \mathrm{mg} / \mathrm{L}$ ) were added to $0.9 \mathrm{~mL}$ of the aqueous LC phase. All experiments were performed in duplicate. Tests with $1 \mathrm{~L}$ of doubly distilled water were performed as blank controls simultaneously with every series of experiments. Pure quartz sand was used as blank material in order to determine the contribution to e.g. the NPOC. The precision of the pTS leachability was $14.6 \%$ (95\% tolerance interval), determined by performing the experiment with unused formulated sand (eight replicates). Therecovery, the limit of detection, and quantification (LOD/ $\mathrm{LOQ}=3 \times / 10 \times$ standard deviation (16)) of the analytical method were $98 \pm 2.8 \%$ (4 replicates), $6 \mathrm{mg} / \mathrm{L}$ (10 replicates), and $20 \mathrm{mg} / \mathrm{L}$ (10 replicates), respectively. The data were determined by carrying out the tests with doubly distilled water spiked with pTS.

Modified OECD Screening Test $301 E$. All equipment was autoclaved $\left(121{ }^{\circ} \mathrm{C}, 20 \mathrm{~min}\right)$ prior to use. The tests were conducted in $500 \mathrm{~mL}$ clear glass conical flasks closed with a piece of cotton. Leachate $(0.5 \mathrm{~mL})$ was added to $200 \mathrm{~mL}$ of growth medium that was prepared according to the OECD guideline. All solutions were autoclaved $\left(121^{\circ} \mathrm{C}, 20 \mathrm{~min}\right)$ or presterilized by passagethrough sterile disposablefilters $(0.2$ $\mu \mathrm{m}$, cellulose nitrate, Schleicher \& Schuell GmbH, Dassel, Germany). pTS (81 mg/L) or the hardener GRC (130 mg/L) was added into the corresponding flasks. At the beginning of the incubation, the $\mathrm{pH}$ was controlled and adjusted with concentrated o-phosphoric acid when outside the range of 7-8. All batch cultures were incubated in the dark at a constant temperature of $25^{\circ} \mathrm{C}$ and aerated by shaking. The first sampling was $2 \mathrm{~h}$ after the onset of experiments. During the first 2 days, samples were taken every $4 \mathrm{~h}$ and then after an additional 20,80 , and $120 \mathrm{~h}$. The samples for the NPOC determination were taken every second time together with thesamplingfor the LC/ UVD analysis. After filtration through $0.45 \mu \mathrm{m}$ cellulose nitrate membrane filter, $1 \mathrm{~mL}$ of the test solution each was stabilized with $10 \mu \mathrm{L}$ of formaldehyde for the LC/UVD analyses.

Biological activity was tested with p-sulfobenzoate (PSB, $84 \mathrm{mg} / \mathrm{L}$ ) as reference compound. Abiotic elimination was investigated with batch cultures containing $1 \%(v / v)$ of formaldehyde. The mineral medium inoculated with leachate only was used as blank control. The degradation tests were carried out in duplicate and the test controls with onesample each. Recovery, precision, and LOQ of the analytical method were determined by spiking the growth medium with pTS and PSB. The precision was $0.76 \%$ for pTS and $0.45 \%$ for PSB. The recovery was $99.5 \pm 0.98 \%$ for pTS and $101.1 \pm 0.37 \%$ for PSB, and the LOQ (LOQ = 10x standard deviation (16)) was $0.01 \mathrm{mg} / \mathrm{L}$ and $0.02 \mathrm{mg} / \mathrm{L}$ for $\mathrm{pTS}$ and PSB, respectively.

NPOC. The NPOC was determined according to the procedureDIN $38409 \mathrm{H} 3$. Prior to measurement, theleachant samples were diluted 2.5 times with water (desalinated and low in organic carbon). The $\mathrm{pH}$ was adjusted to $2-3$, and the inorganic carbon $\left(\mathrm{CO}_{2}\right)$ was stripped out with a stream of nitrogen during $5 \mathrm{~min}$. The injection volume was $25 \mu \mathrm{L}$.

TOC. The TOC of the foundry sands was determined by the subtraction of the inorganic carbon (IC) from the total carbon (TC), which were separately determined. The sample weights ranged between 30 and $660 \mathrm{mg}$ depending on the carbon content expected. For the IC, $0.7 \mathrm{~mL}$ of o-phosphoric acid ( $25 \%)$ was added to a sample in order to transform the inorganic carbon to $\mathrm{CO}_{2}$, which was driven out at a temperature of $250^{\circ} \mathrm{C}$ and measured. Subsequently, the TC was determined by combusting the residue to $\mathrm{CO}_{2}$ at a temperature of $890^{\circ} \mathrm{C}$.

Total Solids and Fixed Solids. The total solids dried at $105^{\circ} \mathrm{C}$ and the fixed solids ignited at $550^{\circ} \mathrm{C}$ of thetest material were determined according to the standard procedure DIN 38414 S3 and DIN 38414 S2, respectively. The volatile solids corresponded to the difference between the total weight and fixed solids.

LC/UVD. The LC column $(250 \times 4 \mathrm{~mm})$ and the precolumn $(5 \times 4 \mathrm{~mm})$ used was a Hypersil ODS, with $5 \mu \mathrm{m}$ particles (Knauer $\mathrm{GmbH}$, Berlin, Germany). The aqueous LC phase was $5 \mathrm{mM}$ TBA buffered with $10 \mathrm{mM}$ phosphate at $\mathrm{pH}$ 6.5. The organic modifier was $\mathrm{MeOH}$. A stream of Helium degassed the eluent for $30 \mathrm{~min}$ prior to the measurements. The column was kept at $40^{\circ} \mathrm{C}$ and conditioned with $10 \mathrm{~mL}$ of the initial eluent composition. The flow rate was $1 \mathrm{~mL} /$ min. The backpressure ranged from 150 to 190 bar at the start of the analyses. The elution mode was a linear gradient from $20 \%$ to $50 \% \mathrm{MeOH}$ in $15 \mathrm{~min}$ (leaching test) and from $20 \%$ to $40 \% \mathrm{MeOH}$ in $20 \mathrm{~min}$ (biodegradation test). The injection volume was $125 \mu \mathrm{L}$ (leaching test) and $200 \mu \mathrm{L}$ (biodegradation test). The UV absorption wavelengths monitored were 220 and $294 \mathrm{~nm}$. The absorption spectra were recorded in the range of $210-400 \mathrm{~nm}$.

LC/MS. The chromatographic method was the same as applied for the LC/UVD analyses except that $10 \mathrm{mM} \mathrm{NH}{ }_{4} \mathrm{Ac}$ ( $\mathrm{pH}$ 6.8) was used as the aqueous phase. A linear gradient was run from $1 \%$ to $20 \% \mathrm{MeOH}$ in $20 \mathrm{~min}$. The backpressure at the onset of an analysis was 56-87 bar. The injection volume was $25 \mu \mathrm{L}$ or $50 \mu \mathrm{L}$. Full mass spectra were acquired in negativeion mode, scanning from $\mathrm{m} / \mathrm{z50}-600$ at $1 \mathrm{~s} / \mathrm{scan}$. 
A)

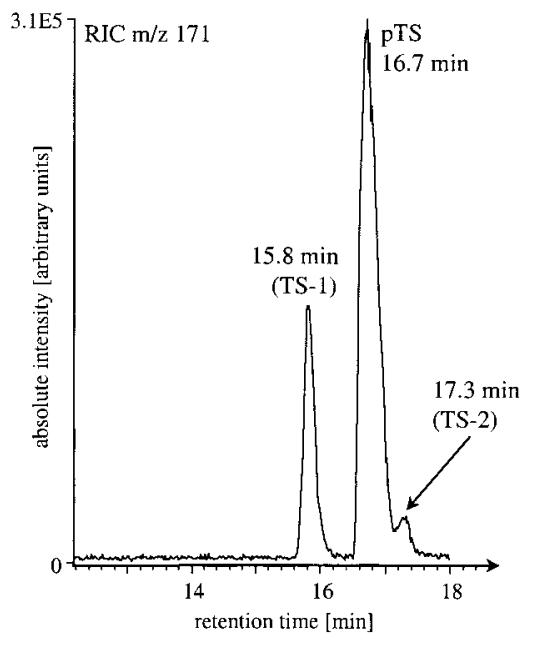

B)

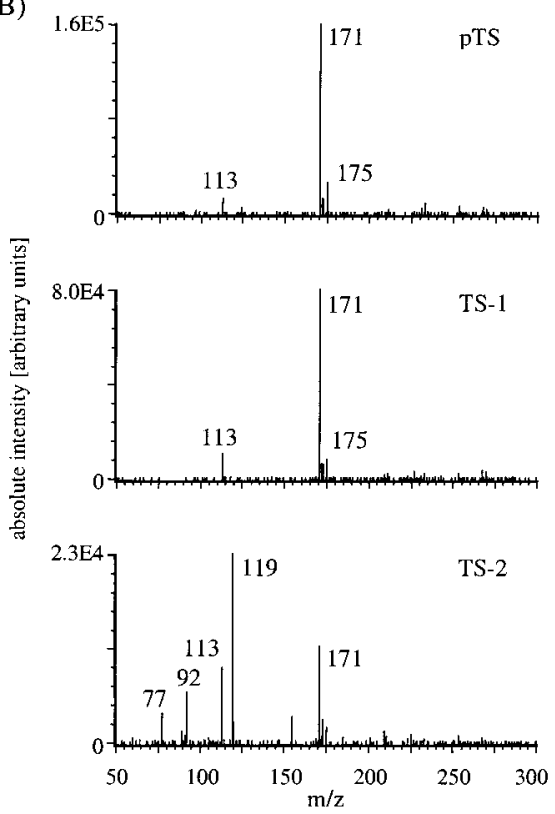

C)
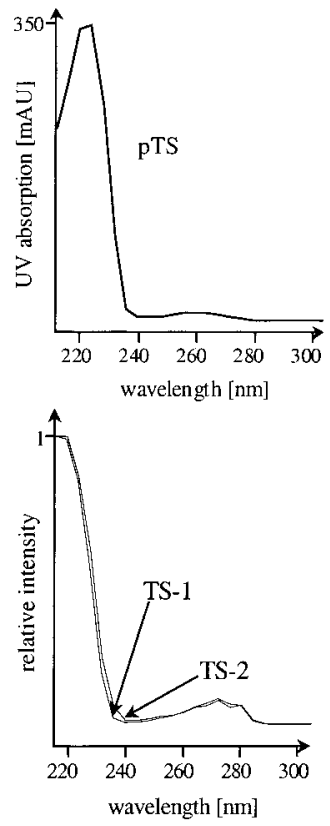

FIGURE 1. Product analysis of the hardener GRC: (A) Reconstructed ion chromatogram (RIC) for $\mathrm{m} / \mathrm{z} \mathbf{~ 1 7 1}$. The three signals correspond to $p$-toluenesulfonate (pTS) and $m$ - and 0 -toluenesulfonate (TS-1 and TS-2). (B) M ass spectra obtained from the LC/M S signals at 16.7 min (pTS), $15.8 \mathrm{~min}$ (TS-1), and 17.3 $\mathrm{min}$ (TS-2). ( $\mathrm{m} / \mathrm{z} 119$ acetic acid-acetate cluster, $\mathrm{m} / \mathrm{z}$ 77, 92, 113, and 175 are unknow $\mathrm{n}$ matrix ions). (C) UV absorption spectra acquired using the same separation method as for the LC/MS analysis.

The multiplier was set to $750 \mathrm{~V}$. The so-called "pepper pot" was used as the counter electrode. The needle voltage was $-3 \mathrm{kV}$, and the cone voltage was set to $0 \mathrm{~V}$. High and low mass resolution both were set to 14; the ion energy was 1. The interface temperature was $150^{\circ} \mathrm{C}$, and the nitrogen gas flow was $500 \mathrm{~L} / \mathrm{h}$. The mass range was calibrated, and the sensitivity of the instrument was checked using $0.5 \mathrm{mM}$ Csl in water/MeOH (1:1) and infused at a flow rate of $20 \mu \mathrm{L} / \mathrm{min}$, using a Harvard Syringe pump model '22' (Harvard Instrument, Gams Switzerland).

Quantification. The T-2,4-dS concentrations of the environmental samples could only roughly be estimated because of the unknown purity of the synthesized product. TC and IC were quantified with the reference compound $\mathrm{D}(+)$ glucose and potassium hydrogen carbonate, respectively. In the biodegradation tests, the relative decrease of the compound concentration was determined by normalizing the signal areas to the maximum peak area. The NPOC concentration decrease was calculated relative to the initial content taking into account the concentrations of the blank controls. The loss of water caused by evaporation ( $1 \mathrm{~mL} /$ week) was included in all calculations. The adaptation and degradation phase corresponds to the time period required for the elimination to $90 \%$ and from $90 \%$ to $30 \%$ of the initial compound concentration.

\section{Results and Discussion}

The Hardener GRC. The pTS solution used as hardener for the production of furanic resin-bonded foundry moulds and cores was assumed as potential source of pTS in the landfill leachates. Since the hardener is of technical quality, other sulfonated landfill pollutants could also derive from it. For this reason, the hardener GRC was examined for byproducts using LC/MS and LC/UVD (dilution factor: 20000 for MS detection, 120000 for UVD). As described in ref 9, the hardener contained all three positional isomers of toluenesulfonate (TS) as shown in Figure 1a. Although no reference substances were available, the signals at $15.8 \mathrm{~min}$ (TS-1) and $17.3 \mathrm{~min}$ (TS-2) were attributed to o- and $\mathrm{m}$-TS based on their mass spectra (Figure 1b) and very similar UV absorption

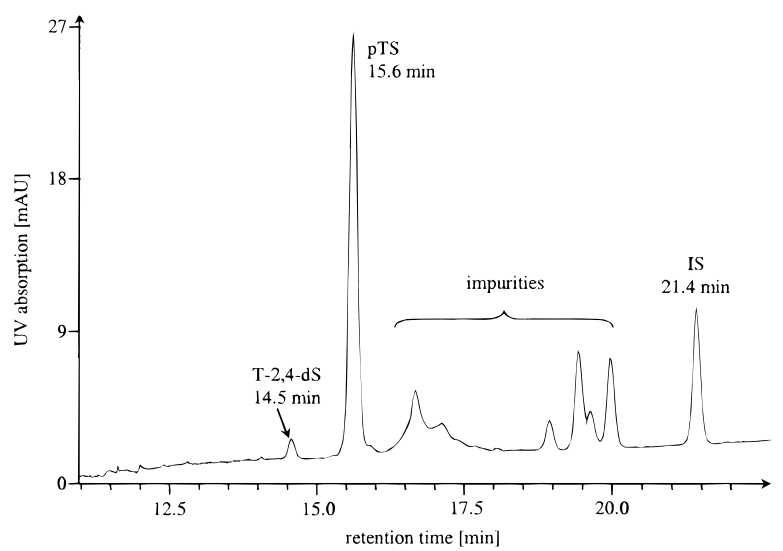

FIGURE 2. Leaching test: LC/UVD chromatogram $(220 \mathrm{~nm})$ obtained from a leachant of the test DIN 38414 S4 with a furanic resinbonded sand as test material. The corresponding mould $w$ as formed w ith internally recycled sand and used for casting (internal standard (IS): diphenylamine-4-sulfonate).

spectra (Figure 1c). The latter were obtained by substiuting an UVD for the MS, whileusing the LC/ MS chromatographic conditions.

The pTS concentration was $573 \pm 1.7 \mathrm{~g} / \mathrm{L}(\mathrm{n}=5)$. The concentrations of TS- 1 and TS- 2 were around $172 \mathrm{~g} / \mathrm{L}$ and $29 \mathrm{~g} / \mathrm{L}$, estimated from the peak area in the reconstructed ion chromatogram for $\mathrm{m} / \mathrm{z} 171$, assuming identical yield for molecular ion formation for all three TS. In addition, BeS and T-2,4-dS were identified as hardener byproducts at a concentration of $10 \pm 1.5 \mathrm{~g} / \mathrm{L}(n=5)$ and about $95 \mathrm{~g} / \mathrm{L}$, respectively.

Foundry Sands. Quartz sand made up $98 \%$ of each test material which is clearly shown by the content of fixed solids after combustion at $550^{\circ} \mathrm{C}$ and the small fraction of volatile solids (Table 1). Unused and used formulated sand from Foundry I were indistinguishable in this assay which means that the burn-out of organic material in the mould-metal contact region (thickness of ca. $3 \mathrm{~mm}$ ) during the casting seems to have negligible effect on the volatile compounds. 
A)

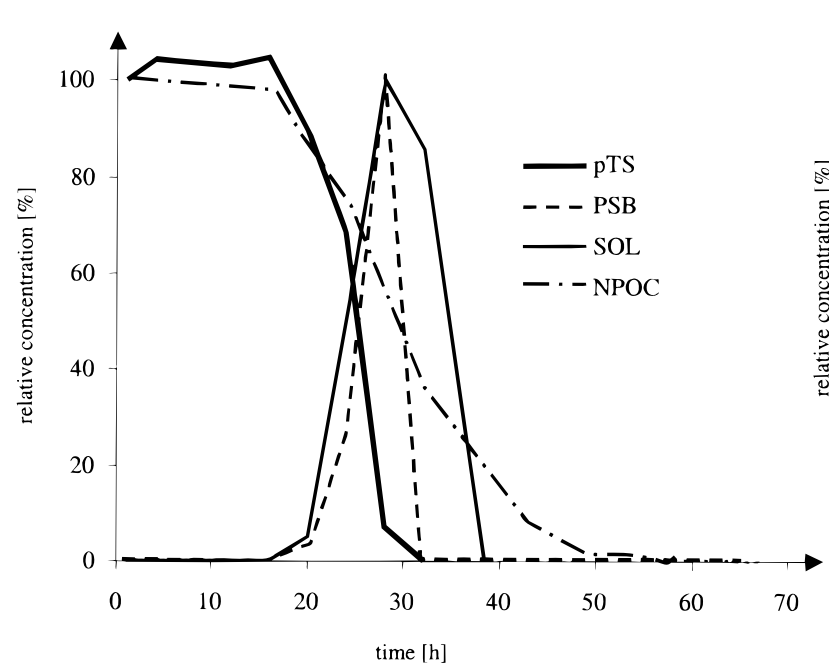

B)

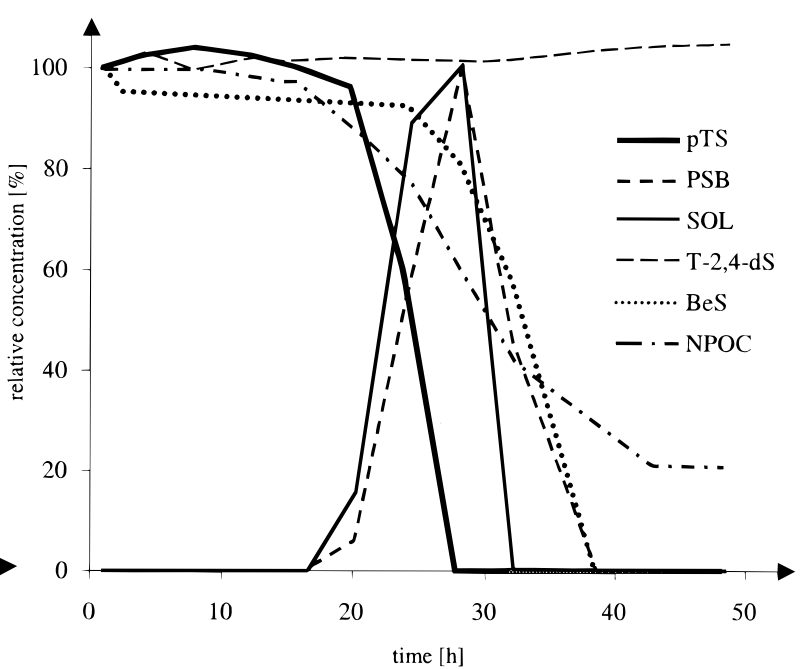

FIGURE 3. Aerobic NPOC elimination and primary degradation (A) of pure $p$-toluenesulfonate (pTS) and (B) of the hardener components pTS, toluene-2,4-disulfonate (T-2,4-dS), and benzenesulfonate (BeS) in a batch culture inoculated with $0.5 \mathrm{~mL}$ leachate. In both setups, the metabolites p-sulfobenzoate (PSB) and p-sulfobenzyl alcohol (SOL) appeared as transients.

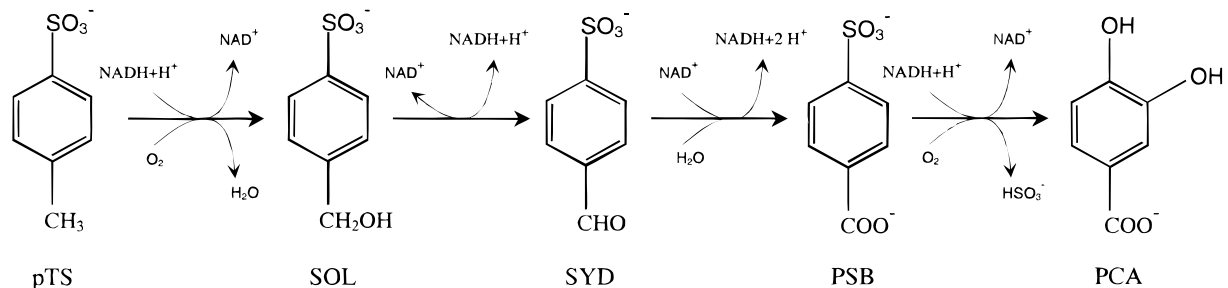

FIGURE 4. Degradation pathw ay of $p$-toluenesulfonate (pTS) by Comamonas testosteroni T-2 (13). The degradation starts with the oxygenation of the methyl-side chain to $p$-sulfobenzyl alcohol (SOL). The subsequent dehydrogenation leads to $p$-sulfobenzaldehyde (SYD) which is oxidized to $p$-sulfobenzoate (PSB). This metabolite is transformed to protocatechuate (PCA) by the ring dioxygenation in the 1,2-position and the spontaneous loss of sulfite, followed by the meta-cleavage of protocatechuate and the formation of pyruvate.

TABLE 1. Characterization of the Foundry Sand Samples, the Leachants of the Test DIN 38414 S4, and the Landfill Leachate

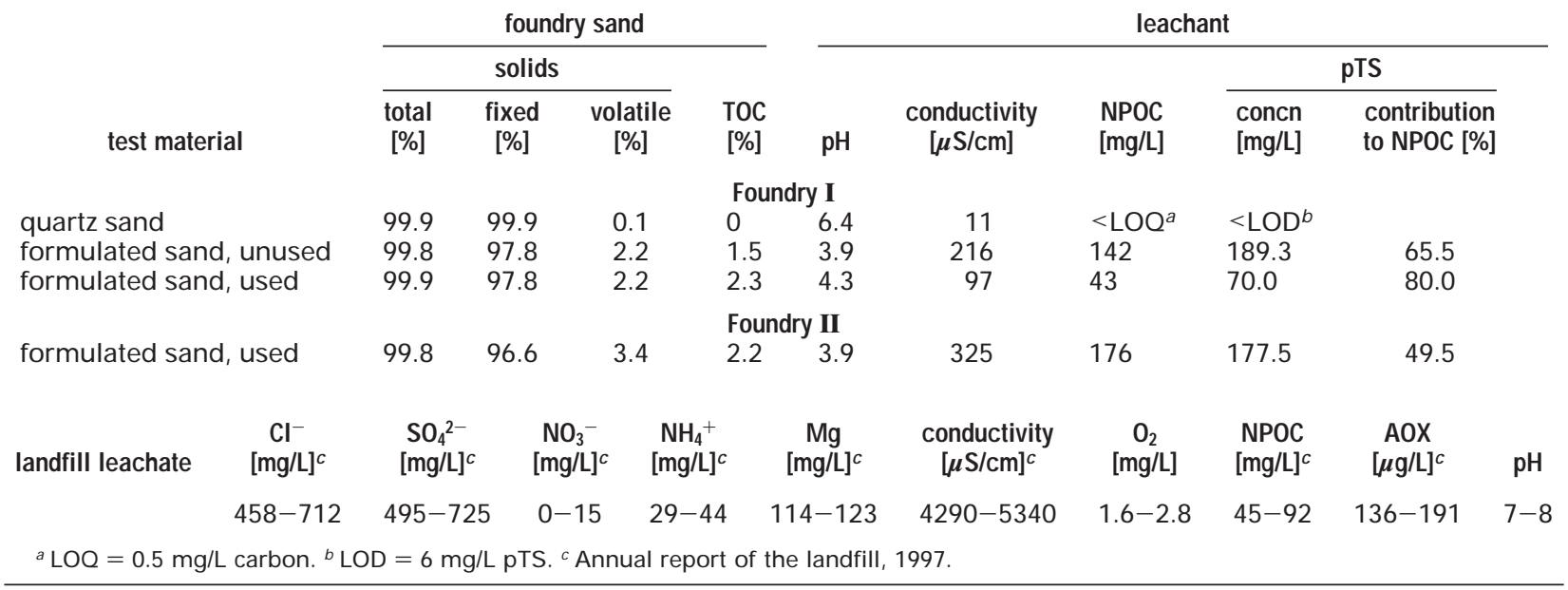

However, the elevated TOC fraction of the sand used for casting cannot be explained with the information available. The increased fraction of volatile solids in the formulated sand from Foundry II could be attributed to the use of internally recycled sand for the production of moulds. This sand still contained organic components from previous applications, as detected in unidentified compounds in the LC/UVD chromatograms of the corresponding leachants (Figure 2).

Leaching Tests. The aim of the leaching tests was to confirm that pTS is leachable from furanic resin-bonded foundry sands, and hencetheir wastes deposited in thelandfill are a source of pTS in the leachates.

Table 1 and Figure 2 show that pTS and T-2,4-dS were released from the formulated sands. pTS represented 49$80 \%$ of the NPOC and was thus the major component in the leachants. Analysis of the test solutions was done by LC/ UVD at a dilution which left BeS and TS-1 below LOD; the presence of the latter compounds was confirmed by LC/MS. Reagent blanks showed that neither pTS nor NPOC was introduced into theleachants by the test procedure. Control experiments with pure quartz sand showed that it contained 
no aromatic sulfonates and negligible volatile solids, TOC, and NPOC (Table 1).

The leachants of used and unused formulated sands from Foundry I differed significantly. The concentrations of pTS and NPOC from used sand were $30 \%$ lower than from unused sand. Pyrolysis and evaporation during contact with hot metal in the mould could possibly explain this difference. pTS and NPOC concentrations were significantly higher in the corresponding samples from Foundry II. The recycled sand in thesemoulds (seeabove) contained unidentified compounds from former applications besides pTS (Figure 2).

The amount of pTS released during the test duration of $24 \mathrm{~h}$ was about $30 \%$ of the pTS originally added in the un used formulated sand $(5.73 \mathrm{~g} / \mathrm{kg}$ pTS). The remaining $70 \%$ was presumably trapped in the furanic resin network, which held the sand grains together. It was impossible to estimate the fraction of pTS released versus pTS still bound in the used sand, because the amount of pTS transformed during the casting procedureis unknown. Nevertheless, theresults show clearly that soluble pTS remained in the used formulated sand.

The NPOC in the leachants corresponded to $1.9-9.5 \%$ of the TOC of all foundry sands tested. The major portion of the organic components in formulated sand was, thus, nonleachable under the test conditions. It is not surprising that the furanic resin should be sparingly soluble in water, given its three-dimensional polymeric structure after hardening.

The $\mathrm{pH}$ values of all leachants from the formulated sands weresignificantly lower than the $\mathrm{pH}$ of pure quartz sand $(\mathrm{pH}$ 6.4 , Table 1). The initial $\mathrm{pH}$ of the binder Gremodur KN was in the range of $6-7$, according to the product specifications. Thus, hardener GRC was the cause for the low $\mathrm{pH}$ values of the leachants.

The effect of the duration of the test on the amount of pTS released was investigated with un used formulated sand. At least $75 \%$ of pTS and of NPOC released during $24 \mathrm{~h}$ was found in the leachant after $1 \mathrm{~h}$, and only an additional $9 \%$ pTS was extracted during a subsequent leaching step for 24 h (1./ 2. leachingstep: 193.8/17.3 mg/L pTS). Hence, unbound pTS was leached very rapidly, apparently without any transport limitations.

Particlesize could influencethepTS concentration in the leachant. Tests with unused formulated sand of different sizefractions ( $<0.5 \mathrm{~mm}, 0.5-1 \mathrm{~mm}, 1-5 \mathrm{~mm}$, and $5-10 \mathrm{~mm}$ ) showed no significant effect of the grain size on the pTS concentration in the leachant which ranged between 191.1 and $216.6 \mathrm{mg} / \mathrm{L}$. This can be attributed to the homogeneous structure and the high porosity of the test material in its crushed form.

Aerobic Biodegradation Tests. Biodegradation tests were conducted with leachate collected from a drain section where atmospheric oxygen was present in order to screen for microorganisms using pTS, BeS, or T-2,4-dS. No biodegradation was expected to occur in the landfill due to high salt concentrations, low oxygen concentration (Table 1), and the potential presence of toxic components.

The biological activity of the leachate as inoculum was tested with $65 \mathrm{mg}$ of PSB/L, according to Altenbach (5), who has shown its ready biodegradability under similar test conditions. NPOC and PSB were degraded simultaneously within $13 \mathrm{~h}$ (NPOC) and $11 \mathrm{~h}$ (PSB) after an adaptation phase of 25 and $29 \mathrm{~h}$, respectively. PSB was fully converted to cell material and $\mathrm{CO}_{2}$, as shown by the fact that no significant NPOC remained. The NPOC content of the inoculum ranged between 1.5 and $6.8 \mathrm{mg} / \mathrm{L}$ carbon. No blanks contained target compounds, intermediates, or substances causing interference, and no abiotic elimination of the test or reference compounds was detected in biological controlssterilized with formal dehyde.
The inoculated leachate microorganisms degraded pTS completely within 6-7 h after an adaptation phase of less than 1 day in the batch cultures with pTS as sole carbon source $(81 \mathrm{mg} / \mathrm{L})$ (Figure 3a). However, the elimination of NPOC to completion took twice as long. Theslower decrease of NPOC was caused largely by two transient intermediates, which were detected by LC/UVD. One transient coeluted with PSB and displayed the same UV-spectrum as PSB. Its concentration varied between $0.3 \mathrm{mg} / \mathrm{L}$ and $7.0 \mathrm{mg} / \mathrm{L}$. The other transient eluted at a retention time of $6.5 \mathrm{~min}$. Its UV spectrum corresponds to that of p-sulfobenzyl al cohol (SOL) (17), which is excreted during growth with pTS of all organisms known to contain the tsa genes (18). The occurrence of SOL and PSB as transient intermediates indicated that bacteria are present in the landfill leachatethat degraded pTS via the pathway found for Comamonas testosteroni T-2 (Figure 4).

Because BeS and T-2,4-dS were also identified in the landfill leachate(8), thequestion arises if they arealso utilized by the leachate microorganisms, even in the presence of pTS. For this reason, the degradation of the hardener GRC (63 mg/ L pTS, $12 \mathrm{mg} / \mathrm{LT}-2,4-d S, 1.5 \mathrm{mg} / \mathrm{LBeS}$ ) was examined. First, pTS was degraded as in the tests, with the pure substancewith the transient excretion of SOL and PSB (Figure $3 b$ ). The concentration of the transient PSB ranged between 0.3 and $5.7 \mathrm{mg} / \mathrm{L}$. BeS, PSB, and SOL all disappeared simultaneously. In addition, the elimination of TS-1 and TS-2 could be measured by LC/UVD, but only after pTS had vanished because pTS and TS-1 coeluted at the given analytical conditions. Thus, all three positional isomers of TS disappeared in theorder pTS, TS-2, and TS-1. In contrast, T-2,4-dS was not degraded during the wholeincubation. The NPOC of the test solutions decreased by $80 \%$ during the first 2 days, caused mainly by the pTS degradation. The subsequent gradual decline to $9-13 \%$ of the initial NPOC-values indicates full degradation of BeS, TS-1, and TS-2. At the end of the experiments, the residual NPOC was $3-5 \mathrm{mg} / \mathrm{L}$, probably derived from the persistent T-2,4-dS.

The degradation of pTS, BeS, TS- 1 , and TS- 2 in batch cultures using the oxic landfill leachate collected at the drain end as test solution without any supplementation confirmed the presence of bacteria that degrade these compounds even under not optimum conditions (data not shown).

In conclusion, the high concentrated pTS in the leachate from landfill sections containing foundry wastes derive from the hardener used to prepare the moulds and cores. Other sulfonated leachatepollutants such as BeSand T-2,4-dScould also betraced back to byproducts of this hardener. Although most of the leached pTS is transferred into the local sewage treatment plant, a minor fraction is degraded by aerobic microorganisms present in the oxic landfill leachate. Indeed, a known degradative pathway for pTS was found to be active in vivo. These bacteria also utilized the hardener byproducts BeS and both other positional TS isomers but not T-2,4-dS. Especially, the persistence of T-2,4-dS emphasizes the requirement to evaluate impurities as well as the nominal component(s) in environmental assessments of commercial products.

\section{Acknowledgments}

We thank Mr. Meienberg for his help in collection samples from thelandfill site. Valuablecomments weremadeby HansPeter Füchslin. Drs. A. C. Johnson, A. Alder, and T. Egli are greatly acknowledged for reviewing the manuscript.

\section{Literature Cited}

(1) Lange, F. T.; Wenz, M.; Brauch, H.-J. AMI 1995, 2(5), 277-284.

(2) Neitzel, P. L.; Abel, A.; Grischek, T.; Nestler, W.; Walther, W. Vom Wasser 1998, 90, 245-271. 
(3) Zerbinati, O.; Vincenti, M.; Pittavino, S.; Gennaro, M. C. Chemosphere 1997, 35, 2295-2305.

(4) Kölbener, P.; Baumann, U.; Cook, A. M.; Leisinger, T. Water Res. 1994, 28, 1855-1860.

(5) Altenbach, B. Ph.D. Dissertation ETH No. 11 437, Swiss Federal Institute of Technology, Switzerland, 1996.

(6) Zerbinati, O.; Salomone, S.; Ostacoli, G. Chemosphere 1994, 29, 2939-2643.

(7) Betowski, L. D.; Kendall, D. S.; Pace, C. M.; Donnelly, J. R. Environ. Sci. Technol. 1996, 30, 3558-3564.

(8) Riediker, S.; Suter, M. J.-F.; Giger, W. Water Res. 2000, 34, 20692079.

(9) Beratergremium für umweltrelevanteStoffep-Toluolsulfonsäure; VCH: Weinheim, 1991.

(10) Bradke, H.-J. Giesserei 1975, 62(5), 103-105

(11) Bradke, H.-J. Giessere 1978, 65(2), 35-38.

(12) Bradke, H.-J.; Hansonis-Jouleh, H. Untersuchungen zur umweltrelevanten Beurteilung von Formstoffen für dieForm- und Kernherstellung in Giessereien, Teil III; Institut für gewerbliche Wasserwirtschaft und Luftreinhaltung e.V.: Köln, 1993.
(13) Cook, A. M.; Laue, H.; Junker, F. FEMSMicrobiol. Rev. 1999, 22, 399-419.

(14) Riediker, S. Ph.D. Dissertation ETH No. 12 974, Swiss Federal Institute of Technology, Switzerland, 1999.

(15) Suter, M. J.-F.; Riediker, S.; Giger, W. Anal. Chem. 1999, 71(4), 897-904.

(16) Taylor, J. K. QualityAssuranceof Chemical Measurements; Lewis Publishers: Chelsa, MI, 1987.

(17) Locher, H. H.; Leisinger, T.; Cook, A. M. J. General Microbiol. 1989, 135, 1969-1978.

(18) Junker, F.; Kiewitz, R.; Cook, A. M. J. Bacteriol. 1997, 179, 919927. 